\author{
R. I. Hassink · C. E. Pasquinelli-Egli · V. Jacomella \\ R. Laux-End · M. G. Bianchetti
}

\title{
Conditions currently associated with erythema nodosum in Swiss children
}

Received: 29 April 1997 / Accepted: 26 May 1997

\begin{abstract}
A review was made of the 36 paediatric patients in whom the diagnosis of erythema nodosum had been established between 1977 and 1996 at the Department of Paediatrics, University of Bern, Switzerland. Infectious diseases were associated with erythema nodosum in 20 (including 10 streptococcal infections) and non-infectious inflammatory diseases in 8 patients. None of the 36 patients had tuberculosis or had been exposed to sulphonamides, phenytoin or hormonal contraceptives. There were eight patients in whom either the associated disease was not diagnosed, or there was no other disease.
\end{abstract}

Conclusion Most cases of erythema nodosum are nowadays caused by non-mycobacterial infectious diseases or by non-infectious inflammatory diseases.

Key words Child · Erythema nodosum - Inflammatory bowel disease $\cdot$ Streptococcal infections $\cdot$ Tuberculosis

\section{Introduction}

In childhood erythema nodosum is the most prevalent panniculitis. It has a characteristic clinical picture and the diagnosis can be made on the basis of physical examination alone $[5,6]$. Erythema nodosum has been associated with various infectious and non-infectious disorders [5, 6]. In addition, various pharmacological agents have also been considered responsible for this panniculitis $[5,6]$. The relative weight of the various causes of erythema nodosum is influenced by geographical and racial factors as well by the age of the patients $[1-6,8-10,12]$. Their importance may also vary from

R. I. Hassink · C. E. Pasquinelli-Egli · V. Jacomella

R. Laux-End · M. G. Bianchetti ( $₫)$

Kinderklinik, Inselspital, CH-3010 Bern, Switzerland,

Tel.: + 31 6329479, Fax: + 316329444 ,

E-mail: mbianche@insel.ch time to time [1-6, 8-10, 12]. Previous surveys emphasized mycobacterial and streptocooccal infections as the conditions most often linked with erythema nodosum, but a better control of these diseases is now possible. There have been no general series of cases reported in recent years which might mirror these mutations. The purpose of this study was to review the conditions associated with erythema nodosum in the period 1977 to 1996 as encountered in a paediatric referral hospital in Switzerland.

\section{Patients and methods}

A review was made of all patients aged 16 years or less in whom the diagnosis of erythema nodosum had been established between 1977 and 1996 at the Department of Paediatrics, University of Bern, Switzerland. For this purpose, the clinical and the laboratory records of the Department of Paediatrics and those of the referring family doctors were evaluated in terms of established criteria for the diagnosis of associated conditions. The use of sulphonamides, phenytoin and hormonal contraceptives was expressly inquired. Total white blood cell count, erythrocyte sedimentation rate, tuberculin skin test and chest roentgenography had been performed in all children. Additional investigations were performed in patients with a positive tuberculin test. Information on follow up was obtained directly by the patient or by the referring physicians 6 months or more after the skin lesion had resolved. The results are expressed as median and interquartile range. The $\chi^{2}$-test and the Kruskal-Wallis test were used to analyse the results obtained in the various subgroups of patients. $P<0.05$ was accepted to indicate statistical significance.

\section{Results}

All 36 patients (18 girls and 18 boys, aged between 1.5 and 16 years, median 10 years) were Caucasian. The skin lesions were confined to the shins and knees in 29 cases. In 7 patients the rash was concurrently found on the forearms $(n=7)$ or the face $(n=1)$. Infectious diseases were diagnosed in 20 patients and non-infectious diseases in 8 (Table 1). None of the patients had tuberculosis. There were 8 patients in whom either the associated disease was not diagnosed, or there was no other disease. General information on the three different 
Table 1 Disorders associated with erythema nodosum in 28 out of the 36 patients. In the remaining 8 patients the associated disease was not diagnosed, or there was no other disease

\begin{tabular}{|c|c|}
\hline Condition & Cases \\
\hline \multicolumn{2}{|l|}{ Streptococcal infections } \\
\hline- pharyngitis $^{\mathrm{a}}$ & 8 \\
\hline - impetigo $\mathrm{b}$ & 1 \\
\hline - cellulitis ${ }^{b}$ & 1 \\
\hline \multicolumn{2}{|l|}{ Non-streptococcal respiratory infections } \\
\hline - upper respiratory tract & 2 \\
\hline - lower respiratory tract & 2 \\
\hline Burkholderia cepacia pulmonary infection ${ }^{\mathrm{c}}$ & 1 \\
\hline Parvovirus B19 & 1 \\
\hline Infectious mononucleosis & 1 \\
\hline Infectious gastro-enteritis ${ }^{\mathrm{d}}$ & 3 \\
\hline Ulcerative colitis & 3 \\
\hline Crohn disease & 3 \\
\hline Sarcoidosis & 1 \\
\hline Behçet disease & 1 \\
\hline
\end{tabular}

a $\beta$-haemolytic streptococcus cultured $(n=4)$, strongly increased antistreptolysin titre $(n=2)$ or both $(n=2)$

${ }^{\mathrm{b}} \beta$-haemolytic streptococcus cultured

c Patient with cystic fibrosis

d Yersinia enterocolitica and Salmonella enteritidis each on one occasion

groups of patients appears in Table 2. The patients without associated diagnosis tended to be younger by approximately 5 years than those with associated infectious or non-infectious disease. Duration of the rash was longer by approximately 10 days in patients with an underlying non-infectious disease. In three patients with a non-infectious underlying disease the final diagnosis (each one patient with Crohn disease, Behçet disease or sarcoidosis) was made 2, 3 and 4 months after resolution of the skin lesions. None of the 36 patients had been exposed to sulphonamides, phenytoin or hormonal contraceptives.

Erythema nodosum tended to recur in the patient with sarcoidosis, in one patient with Crohn disease and in one patient with erythema nodosum associated with upper respiratory infection.

\section{Discussion}

The present report indicates that most cases of childhood erythema nodosum are nowadays caused either by non-mycobacterial infectious diseases or by non-infectious inflammatory diseases. The most common infectious precipitating agents are streptococcal infections, non-streptococcal respiratory infections likely caused by unidentified viral agents and other viral or bacterial infections. The most common non-infectious causes are inflammatory bowel diseases, sarcoidosis, Behçet disease or collagen vascular diseases [5-7]. The tendency for erythema nodosum to occasionally antedate other manifestations of non-infectious systemic diseases noted in this survey corroborates the data of the literature [7]. In spite of information on follow up for at least 6 months there was a large minority of patients in whom the associated disease was not diagnosed, or there was no other disease $[1-6,8-10,12]$.

Sulphonamides, phenytoin and hormonal contraceptives have also been considered responsible for erythema nodosum in adulthood [5,6] but none of our paediatric patients had been exposed to these agents.

In the past, tuberculosis was the foremost cause of erythema nodosum but in this survey tuberculosis failed to account for erythema nodosum [1-6, 8-10, 12]. After decades of decline in the incidence, the number of tuberculosis cases has tended to increase over the last years in Switzerland as a consequence of the immigration from high prevalence countries and the outbreak of human immunodeficiency virus $[11,13]$. It is therefore assumed that tuberculosis still deserves consideration in children with erythema nodosum $[5,6]$.

Table 2 Conditions associated with erythema nodosum in 36 paediatric patients. Results are given as median [interquartile range between brackets]

\begin{tabular}{|c|c|c|c|c|}
\hline & $\begin{array}{l}\text { Infectious } \\
\text { diseases }\end{array}$ & $\begin{array}{l}\text { Non-infectious } \\
\text { diseases }\end{array}$ & $\begin{array}{l}\text { No associated } \\
\text { diagnosis }\end{array}$ & All \\
\hline Cases & 20 & 8 & 8 & 36 \\
\hline Age, years & $10[18.8-13]$ & $11[10-14]$ & $4.8^{\mathrm{a}}[3.4-8.4]$ & $9.6[5.3-13]$ \\
\hline \multicolumn{5}{|l|}{ Clinical findings } \\
\hline Fever $^{\mathrm{b}}$ & 13 & 4 & 3 & 20 \\
\hline Arthralgia without synovitis & 6 & 2 & 2 & 10 \\
\hline \multicolumn{5}{|l|}{ Laboratory findings } \\
\hline Elevated white cell count ${ }^{\mathrm{c}}(n)$ & 9 & 5 & 2 & 16 \\
\hline Left $\operatorname{shift}^{\mathrm{d}}(n)$ & 4 & 3 & 0 & 7 \\
\hline Elevated sedimentation rate $^{\mathrm{e}}(n)$ & 15 & 8 & 3 & 26 \\
\hline
\end{tabular}

\footnotetext{
${ }^{a}$ Versus the remaining groups

b $>38.0^{\circ} \mathrm{C}$

${ }^{c}$ Leucocytes $>15 \times 10^{9} / 1$

d Nonsegmented polymorphonuclear leucocytes $>15 \%$

e $>30 \mathrm{~mm} / \mathrm{h}$
} 
It is concluded that in Switzerland most cases of childhood erythema nodosum are nowadays caused either by non-mycobacterial infectious diseases or by noninfectious inflammatory diseases.

\section{References}

1. Blomgren SE (1972) Conditions associated with erythema nodosum. N Y State J Med 72:2302-2304

2. Chiappo GF, Balbo L, Picco V, Licata D, Mignone F, Bo C (1977) L'eritema nodoso nell'infanzia. Inquadramento diagnostico e contributo casistico. Arch Sci Med (Torino) 134:253274

3. El Zawahry M (1971) Erythema nodosum: a study of 60 cases. Int J Dermatol 10:145-150

4. Fernandes NC, Maceira J, Muniz M (1994) Erythema nodosum: prospective study of 32 cases. Rev Inst Med Trop Sao Paulo 36:507-513
5. Fox MD, Schwartz RA (1992) Erythema nodosum. Am Fam Physician 46: 818-822

6. Hannuksela M (1986) Erythema nodosum. Clin Dermatol 4:88-95

7. Hyams JS (1994) Extraintestinal manifestations of inflammatory bowel disease in children. J Pediatr Gastroenterol Nutr 19:7-21

8. Kibel MA (1970) Erythema nodosum in children. S Afr Med J 44:873-876

9. Laurence B, Stone DGH, Philpott MG, Wright T, Page APM, Harvey CC, Colver T, Gordon RR, Illingworth RS, Lorber J (1961) Aetiology of erythema nodosum in children: a study of a group of paediatricians. Lancet 278:14-16

10. Romero Gonzalez J, Fernandez Ortiz B (1988) Eritema nodoso en la infancia. An Esp Pediatr 29:317-319

11. Shang H, Desgrandchamps D (1995) Tuberkulose in der Schweiz. Praxis 84:1114-1117

12. Similä S, Pietilä J (1965) The changing etiology of erythema nodosum in children. Acta Tuberc Scand 46:159-168

13. Starke JR, Jacobs RF, Jereb J (1992) Resurgence of tuberculosis in children. J Pediatr 120:839-855 